\title{
RELATO DE VIVÊNCIAS DA AGRICULTURA FAMILIAR REALIZADA EM COMUNIDADES RURAIS DO MUNICÍPIO DE CAMETÁ - PA
}

\section{ACCOUNT OF THE EXPERIENCES OF FAMILY FARMING HELD IN RURAL COMMUNITIES OF THE MUNICIPALITY OF CAMETÁ - PA}

\author{
Thaynara Luany Nunes Monteiro ${ }^{1}$; Fiama Renata Souza Monteiro Cunha ${ }^{2}$; Patricia Taila \\ Trindade de Oliveira ${ }^{3}$; João Tavares Nascimento ${ }^{4}$
}

DOI: https://doi.org/10.31692/978-65-991061-7-0.505-507

\section{INTRODUÇÃOO}

O estágio supervisionado de vivência em ambientes da agricultura familiar visa oportunizar experiências profissionais aos acadêmicos do curso de agronomia, na busca da prática de ensino e, ou, técnicas aplicadas pelos agricultores no dia-a-dia de trabalho no campo. É contribuinte para a formação dos discentes, da forma que tomem conhecimento do trabalho desenvolvido em uma propriedade familiar, vivenciando experiências e observando os métodos empregados pelos agricultores no decorrer desenvolvimento dos agroecossistemas (SILVA, 2013). Sendo assim, as atividades de vivência dos discentes junto aos agricultores familiares em comunidades rurais do município de Cametá-PA, proporcionou a turma de Agronomia 2016, do IFPA - Campus Castanhal, realizar observações e reflexões, por meio do acompanhamento do dia a dia dos agricultores, tanto nas atividades de campo por eles realizadas em seus respectivos lotes, como também nas atividades realizadas de maneira coletiva.

\section{RELATO DE EXPERIÊNCIA}

A sistematização do estágio nesse ciclo de estudo do curso, referente ao Eixo Norteador Meio Biofísico Amazônico e o Homem, foi dividida em duas etapas, onde a primeira referiu-se à preparação com a realização de uma oficina de planejamento, quando a metodologia foi construída coletivamente em função das orientações dos professores que lecionam a disciplina de estágio supervisionado de vivência, quando apresentaram as ferramentas metodológicas possíveis, a construção de um questionário norteador segundo as características previamente conhecidas do município a ser realizado o estágio.

O segundo momento ocorreu no período de 26 de janeiro a 06 de fevereiro 2018, contabilizando 12 dias no total. Foi realizado em uma propriedade familiar rural com

\footnotetext{
${ }^{1}$ Agronomia, IFPA - Campus Castanhal, luanynunes6@ gmail.com

${ }^{2}$ Agronomia, IFPA - Campus Castanhal, fiamarenata21@gmail.com

${ }^{3}$ Agronomia, IFPA - Campus Castanhal, patriciatailaoliveira@ gmail.com

${ }^{4}$ Prof $^{\circ}$ Doutor, IFPA - Campus Castanhal, jnascimenton@bol.com.br
} 
dimensões de aproximadamente 150m X 500m, utilizada há de 19 anos, pela família. Situa-se na comunidade de Matias, pertencente ao município de Cametá-Pará, encontrando-se localizado de acordo com as seguintes coordenadas: Latitude $02^{\circ} 14^{\prime} 40^{\prime \prime}$ Sul e Longitude $49^{\circ}$ 29' 45" Oeste. Possui 120.896 mil habitantes (IBGE, 2016).

Para a obtenção dos dados, foram aplicadas as ferramentas metodológicas, como, as caminhadas transversais envolvendo a família, que, contribui com a descrição dos elementos que fazem parte do contexto do espaço, como os rios, estradas, poços, vegetação e possível criação de animais. Na triangulação, que, combinando questionários e observação, contribuiu para o olhar de múltiplas perspectivas, confirmando ou confrontando informações. E, também, a aplicação de questões através do diálogo com os integrantes familiares (BASTISTA, et al. 2017).

Para que se possa entender o funcionamento do estabelecimento agrícola familiar vivenciado, as atividades agrícolas desenvolvidas na unidade de produção, são divididas em subsistemas. O de produção de farinha e derivados da mandioca, e outros produtos que são comercializados em uma feira local.

A família da propriedade rural em que se desenvolveu o estágio é composta por 6 pessoas. Dentre estas, estão, o pai, a mãe e quatro filhos, sendo que as atividades de trabalho agrícola na propriedade são realizadas somente pelos pais, que obtêm toda a renda familiar, com exceção a proveniente do benefício da filha que é especial. A maior parte do trabalho realizado na propriedade ainda é desenvolvida de forma manual, visto que não se tem maquinário a disposição, o que aumenta a carga de trabalho para determinada atividade, como no preparo de área, roçagem, e demais atividades, gerando um problema ainda recorrente à agricultura familiar.

Nos dias em foram realizados o estágio de vivência, pode-se perceber o modo como são usados os recursos naturais na propriedade pelos agricultores. A família, de modo consciente, usa esses recursos retirando apenas o suficiente da floresta que circunda a localidade, praticando o extrativismo vegetal, na maioria de frutíferas nativas para a venda, tais como, Castanha do Pará, bacuri e cupuaçu, que são comercializadas de forma in natura, ou após seus beneficiamentos, obtendo-se bejús, sucos e polpas. Há, também, outras frutas extraídas para consumo próprio como: pequi, ingá e uxi.

Nas sextas-feiras, inicia-se o processo de preparação ou beneficiamento dos produtos a serem comercializados na feira dos agricultores associados a APACC (Associação Paraense de Apoio a Comunidades Carentes), que ocorre no sábado, sendo eles, bolo de macaxeira, bolo de trigo, sucos de cupuaçu e bacuri, chopp (espécie de picolé artesanal preparado dentro 
de pequenos sacos plásticos) de bacuri, polpa de cupuaçu, bejús e farinha de mandioca, eventualmente. A realização dessa feira é feita a cada 15 dias, no centro da cidade de Cametá, onde os agricultores que são transportados por um ônibus que sai da comunidade as 5:00 horas e retorna as 12:00 horas após o termino da feira.

$\mathrm{Na}$ rotina com a família foi possível perceber a existência um grande interesse do agricultor em adquirir novos conhecimentos que venham a contribuir com o aumento da produção ou com a diminuição das perdas, ou seja além dos conhecimentos empíricos eles estão sempre buscando orientações e novidades através de curso de capacitação e palestras, realizados por instituições parceiras da associação a qual estão vinculados APACC.

\section{CONSIDERAÇÕES}

A busca por conhecimento é essencial na agricultura, pois a lavoura está sempre sujeita a riscos, a aquisição de novas técnicas e métodos reduz estes riscos e ainda aumenta a produtividade. A disponibilidade desses conhecimentos ao agricultor familiar deve ser ampliada, através das instituições públicas voltadas para esses trabalhadores, assim como as Universidades e Institutos Federais, visando a melhor integração entre agricultores e acadêmicos, podendo resultar em uma melhor formação profissional, com a troca de informações e conhecimentos já existentes passados por gerações.

É preciso haver uma organização do trabalho dentro do sistema de produção, para um melhor desempenho das atividades realizadas e para que os compromissos da família sejam realizados, com incentivos advindos das associações e do governo.

A vivência proporciona contato com os conhecimentos tradicionais dos agricultores, adquiridos de forma empírica através do contado direto com a natureza, transformando-a em seu benefício, tais conhecimentos também são fundamentais para a preservação do meio ambiente.

\section{REFERÊNCIAS}

BATISTA, M, G,; MELO, A. T. M.; COELHO, R. F. R.; Guia Metodológico, Estágio Supervisionado De Vivência Do Curso De Agronomia Do IFPA Campus Castanhal. 2017.

IBGE - Instituto Brasileiro de Geografia e Estatística, 2016. Disponível em: https://cidades.ibge.gov.br. Acesso em: 08 de Março de 2018.

SILVA, P. C. G. O Estágio Supervisionado Como Prática Pedagógica Essencial Na Formação Do Engenheiro Agrônomo. Núcleo de Educação e Distância (Nead) - Unoeste. 2013. 